\title{
Comparación de las técnicas de reacción de polimerasa en cadena en tiempo real y antigenemia para la detección de citomegalovirus en sangre de niños sometidos a trasplantes
}

\author{
Mauricio J. Farfán U., J. Pablo Torres T., Alejandra Vergara A., Gloria Donoso W., \\ Andrea Alba G., Claudia Paris D. y M. Elena Santolaya De P.
}

\section{Comparison of real-time polymerase chain reaction and antigenemia assay to detect cytomegalovirus in pediatric transplants}

Background: Cytomegalovirus (CMV) infections are an important cause of morbidity and mortality in transplant recipient. To date, the antigenemia assay is the most used technique for diagnostic and management of CMV infections. However, quantification of CMV viral load by real time polymerase chain reaction (RT-PCR) has becoming the method of choice to detect CMV in a rapid, sensitive and specific manner. Objective: To compare antigenemia and RT-PCR assays in the detection of CMV in blood sample from solid organ and bone marrow transplant (BMT) in children attended at the Dr. Luis Calvo Mackenna Hospital. Methods: In a prospective study, we detect the presence of CMV in blood sample by RT-PCR and antigenemia assays. Results: We analyzed 219 blood samples from 68 children subjected to kidney, liver and BMT. Out of 219 samples analyzed, 147 were negative and 33 were positive for CMV by both techniques. Thirty-seven samples were positive only by RT-PCR and 2 by antigenemia. Considering the antigenemia as a reference, RT-PCR shows $94 \%, 80 \%, 34 \%$ and $99 \%$ sensitivity, specificity, positive and negative predictive values, respectively. The kappa coefficient between both techniques was 0.528. Conclusion: Quantitative determination of CMV viral load by RT-PCR is a sensitive technique with excellent negative predictive value compared to antigenemia. Our results support the use of RT-PCR as a technique that might facilitate the diagnostic and treatment of active CMV infection in pediatric transplants.

Key words: Cytomegalovirus, real time polymerase chain reaction, viral load, antigenemia, solid organ transplant, bone marrow transplant.

Palabras clave: Citomegalovirus, reacción de polimerasa en cadena en tiempo real, carga viral, antigenemia, trasplante de órganos sólidos, trasplante de precursores hematopoyéticos.

\section{Introducción}

$\mathrm{E}$ 1 citomegalovirus (CMV) es causa frecuente de infecciones asintomáticas en pacientes inmunocompetentes; sin embargo, en pacientes inmunocomprometidos puede producir enfermedad grave y potencialmente mortal, en especial en aquellos sometidos a trasplante de precursores hematopoyéticos (TPH) o de órganos sólidos ${ }^{1}$. En TPH alogénicos, se ha descrito que hasta $35 \%$ de los receptores pueden presentar infección activa por $\mathrm{CMV}^{2}$, mientras que en trasplante de órganos sólidos, se ha descrito una incidencia de infección activa y enfermedad por CMV de 36 y $19 \%$, respectivamente ${ }^{3}$. Estas frecuencias de infección hacen necesario contar con métodos de detección rápidos y precisos.

En la última década se han desarrollado técnicas que han optimizado la detección de CMV en sangre en pacientes en riesgo de enfermedad grave ${ }^{4}$. Para el ma- nejo de la infección activa por CMV en esta población puede indicarse la profilaxis con ganciclovir o bien la terapia anticipatoria (en inglés pre-emptive therapy) con seguimiento de la carga de CMV en sangre a través de las técnicas de antigenemia o reacción de polimerasa en cadena en tiempo real (RPC-TR). La detección del antígeno pp65 en los leucocitos de sangre periférica mediante inmunofluorescencia indirecta (IFI) o antigenemia ha sido la técnica más utilizada para el monitoreo y tratamiento de la infección activa por CMV en pacientes inmunocomprometidos en nuestro país. No obstante, esta es una técnica laboriosa que requiere un rápido procesamiento de la muestra, no puede ser automatizada y está sujeta a la interpretación del operador ${ }^{5}$. La RPCTR, por su parte, ha demostrado una mayor sensibilidad y permite evaluar la respuesta al tratamiento antiviral en la infección activa por CMV, siendo especialmente útil en su detección precoz en sangre, líquido cefalorraquídeo y
Facultad de Medicina, Universidad de Chile, Santiago.

Centro de Estudios Moleculares, Departamento de Pediatría y Cirugía Infantil, Campus Oriente, Hospital Dr. Luis Calvo Mackenna, (MJFU, JPTT, AVA, MESDP).

Hospital Dr. Luis Calvo Mackenna, Santiago, Chile. Unidad de Infectología Pediátrica (JPTT, MESDP).

Laboratorio de Microbiología (GDW).

Unidad de Trasplante de Órganos Sólidos (AAG).

Unidad de Trasplante de Medula Ósea (CPD).

Conflicto de interés: Los autores de claran no tener conflictos de interés. Financiamiento: El presente trabajo no tiene financiamiento.

Recibido: 23 de agosto de 2010 Aceptado: 4 de febrero de 2011

Correspondencia a: Mauricio J. Farfán Urzúa mfarfan@med.uchile.cl 
otros fluidos ${ }^{6-7}$. Li y cols ${ }^{8}$, han sugerido un valor de corte de 1.000 copias de ADN viral de CMV por mililitro de sangre para iniciar terapia antiviral en pacientes con alto riesgo de enfermedad por este agente. En Chile, Paris y cols, han comunicado tasas de infección activa por CMV y pronóstico de la enfermedad en niños sometidos a TPH similares a los de países industrializados ${ }^{9}$. A pesar de las promisorias aplicaciones de la cuantificación de ADN viral de CMV mediante RPC-TR, aún es necesario estandarizar adecuadamente esta técnica en cada centro que la realice, para dar validez a los resultados obtenidos de las muestras clínicas y determinar valores de corte adecuados. Hasta la fecha, en nuestro país no se conoce la relación entre los valores entregados por la antigenemia y aquellos obtenidos por RPC-TR.

Tomando en cuenta estos antecedentes, el objetivo de este trabajo es comparar las técnicas de antigenemia y RPC-TR en su capacidad de detección de CMV en sangre de niños inmunocomprometidos sometidos a TPH o de órganos sólidos.

\section{Materiales y Métodos}

Diseño general del estudio. Prospectivo, comparativo, de monitorización de infección activa por CMV. Se analizaron muestras de sangre de niños sometidos a trasplante de riñón (TR), hígado (TH) y TPH atendidos en el Hospital Dr. Luis Calvo Mackenna (HLCM) entre los meses de marzo y agosto del año 2009. Las muestras incluidas correspondieron a aquellas solicitadas en forma habitual en casos de sospecha o seguimiento de enfermedad por CMV. Se excluyeron todas las muestras de pacientes no sometidos a trasplantes. En todas las muestras incluidas se determinó, en forma paralela, la presencia de CMV utilizando las técnicas de RPC-TR y antigenemia.

Antigenemia para citomegalovirus. La detección del antígeno pp65 en leucocitos polimorfonucleares (PMNs) de sangre periférica se realizó utilizando un anticuerpo monoclonal marcado dirigido contra una proteína de matriz viral utilizando el kit Anti Human Cytomegalovirus Immediate Early Antigen, de acuerdo a instrucciones entregadas por el fabricante (Argene). Se realizó el conteo de células positivas a través de IFI y los resultados se expresaron como núcleos positivos en la lectura de 400.000 PMNs. Se consideró una muestra como positiva con un recuento de dos o más núcleos fluorescentes por 400.000 PMNs.

Extracción de ADN. Se utilizaron $200 \mu 1$ de sangre total recolectada en tubos con EDTA para la extracción de ADN utilizando el kit de extracción High Pure Viral Nucleic Acid Kit (Roche). La extracción se realizó de acuerdo a instrucciones entregadas por el fabricante y el ADN extraído se resuspendió en un volumen final de 50 $\mu l$ de tampón de elución.

$R P C-T R$. La detección del ADN de CMV se realizó utilizando el kit CMV LCSet versión 2.0, de acuerdo a instrucciones entregadas por el fabricante (Roche). Para la cuantificación del ADN de CMV se utilizó $5 \mu \mathrm{l}$ del ADN extraído y los resultados se expresaron como copias de ADN viral por mililitros de sangre (copias/mL). La curva estándar para la cuantificación de ADN de CMV se realizó utilizando seis diluciones de $\mathrm{ADN}$ de $\mathrm{CMV}$, con un rango lineal de detección desde 500 (límite inferior) a $5 \times 10^{7}$ copias de ADN de CMV. Para el análisis, se consideró como positiva una muestra con valores $\geq$ a 500 copias de $\mathrm{ADN}$ de $\mathrm{CMV} / \mathrm{ml}$ de sangre.

Análisis estadístico. Para determinar la correlación entre los núcleos/400.000 PMNs obtenidos por antigenemia y el número de copias/mL obtenidos por RPC-TR, se utilizó el test de Pearson, de acuerdo a la distribución paramétrica de los datos. Los valores de carga viral de CMV y el número de núcleos en muestras positivas y negativas de antigenemia se compararon utilizando el test de Mann-Whitney, de acuerdo a la distribución no paramétrica de los datos. Se consideró un valor de $\mathrm{p}<$ 0,05 como diferencia estadística significativa. Para los análisis estadísticos se utilizó el programa SigmaStat 3.0 (SPSS Science).

\section{Resultados}

En este estudio se buscó la presencia de CMV mediante antigenemia y RPC-RT en 219 muestras de sangre, provenientes de 68 niños sometidos a trasplantes. De las muestras analizadas, 29, 23 y 16 correspondían a pacientes que recibieron TR, TH, y TPH, respectivamente. La edad promedio de los pacientes correspondió a 8,9 $\pm 5,5$ años, siendo $57 \%$ hombres.

De las 219 muestras analizadas, $35(16 \%)$ y $70(32 \%)$ muestras fueron positivas por las técnicas de antigenemia y RPC-TR, respectivamente. Treinta y tres (15\%) muestras resultaron ser positivas para $\mathrm{CMV}$ por ambas técnicas. Considerando el ensayo de antigenemia como referencia, la sensibilidad, especificidad, valores predictores positivo (VPP) y negativo (VPN) correspondieron a 94, 80, 34 y $99 \%$, respectivamente. El indice kappa entre ambas técnicas fue de 0,528 , lo que muestra una concordancia aceptable entre ambas técnicas. Los resultados de la detección de CMV utilizando ambas técnicas se encuentran detallados en la Tabla 1.

Al relacionar los valores positivos obtenidos por ambas técnicas, se observó una correlación significativa 
$(\mathrm{r}=0,756 ; \mathrm{p}<0,001 ;$ Figura 1$)$. Por otra parte, al comparar las cargas virales obtenidas por RPC-TR, tanto en las muestras con antigenemia positivas como en las negativas, se observó que las muestras con antigenemias positivas presentaron cargas virales mayores (mediana: 29.900 copias $/ \mathrm{mL}$ ) que las obtenidas en aquellas con antigenemias negativas (mediana: 3.225 copias $/ \mathrm{mL}$; $\mathrm{p}<0,001$ ) (Figura 2). En la Figura 3 se representan los valores encontrados en la detección de CMV utilizando antigenemia y RPC-TR en un paciente sometido a TPH seguido durante siete semanas.

\section{Discusión}

En el presente estudio, la comparación de las técnicas de antigenemia y RPC-TR en la detección de CMV en sangre de niños inmunocomprometidos sometidos a TR, TH y TPH mostró una alta sensibilidad y un alto valor predictor negativo para la RPC-TR, además de un índice kappa de concordancia aceptable. Se observó un alto grado de concordancia en los resultados obtenidos por ambas técnicas. Sin embargo, con la RPC-TR se logró detectar ADN de CMV en un mayor número de sujetos. De las 219 muestras analizadas, sólo dos resultaron positivas por antigenemia y negativas por RPC-TR, destacando que en ambos casos la antigenemia mostró valores bajos, cercanos al valor de corte, de 4 y 6 núcleos/400.000 PMN, respectivamente (datos no mostrados). En 33/219 muestras que dieron resultados positivos por ambos métodos, existió una correlación directa y estadísticamente significativa entre el número de núcleos detectados y el número de copias de $\mathrm{ADN}$ viral $(\mathrm{r}=0,75 ; \mathrm{p}<0,01)$, otorgándole consistencia a los resultados encontrados. En aquellos pacientes que tuvieron antigenemia positiva, la carga de ADN viral por RPC-TR fue significativamente mayor (mediana $=29.900$ copias $/ \mathrm{mL}$ ) que los valores encontrados en pacientes con antigenemia negativa (mediana $=3,225 ; \mathrm{p}<0,01$ ).

En Chile, la antigenemia ha sido el método diagnóstico más utilizado para la detección de CMV en sangre en pacientes sometidos a trasplante ${ }^{9}$. En los últimos años, la RPC-TR se ha introducido como la técnica de elección en países desarrollados, desplazando el uso de la antigenemia. Recientemente, una encuesta a 58 centros de trasplantes de Estados Unidos y Canadá, mostró que $82 \%$ de los centros utilizan la RPC-RT para la detección de CMV en trasplante hepático como estrategia de prevención en terapia anticipatoria ${ }^{10}$.

Los resultados encontrados en este estudio son concordantes con los descritos en la literatura internacional. Boeckh y cols ${ }^{11}$, al comparar tres diferentes RPC-TR con la antigenemia, encontraron valores de sensibilidad, especificidad, VPP y VPN similares a los de este estudio. Griscelli y cols ${ }^{12}$, describieron una alta correlación en los

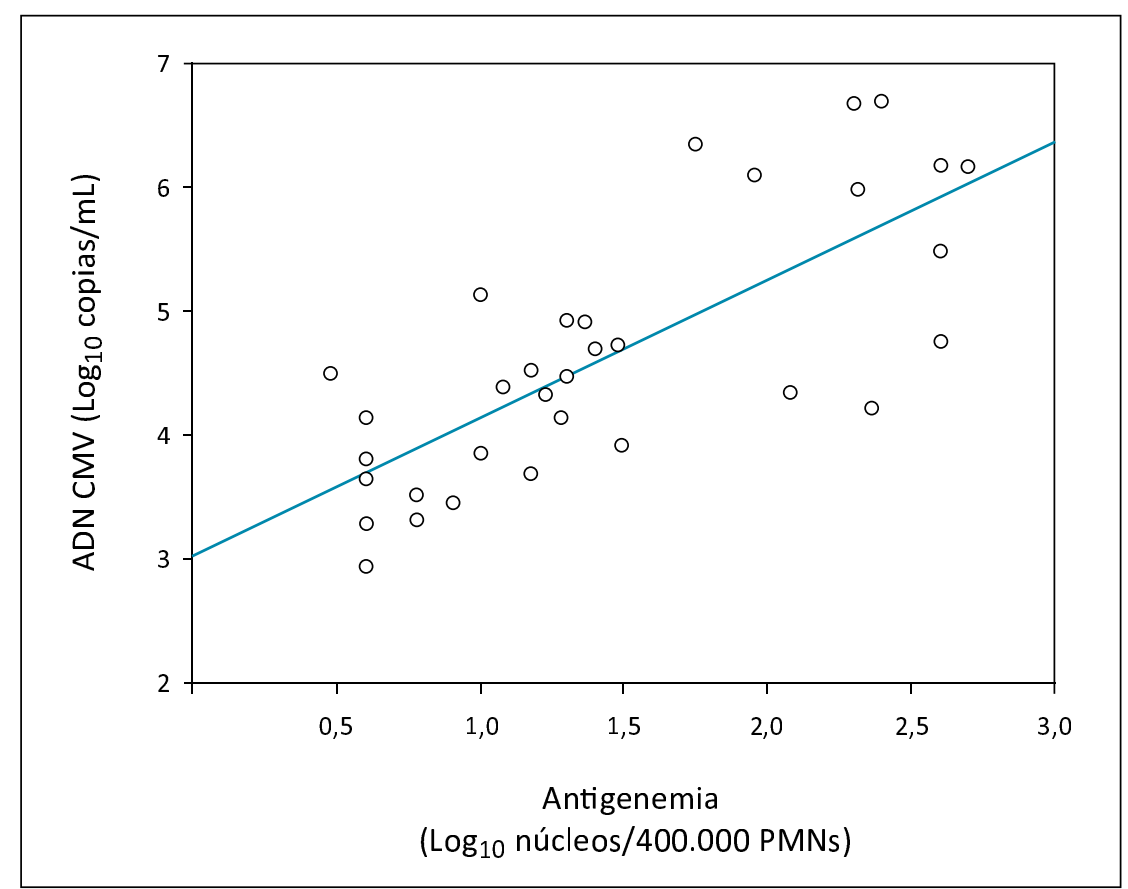

Figura 1. Correlación entre las técnicas RPC-TR y antigenemia. Correlación entre el logaritmo número de núcleos positivos en 400.000 PMNs observados, obtenidos por antigenemia, y el logaritmo del número de copias de ADN de citomegalovirus determinadas por RPC-TR en 33 muestras positivas por ambas técnicas de sangre de niños trasplantados ( $r=0,756, p<0,001$, utilizando el test de Pearson).

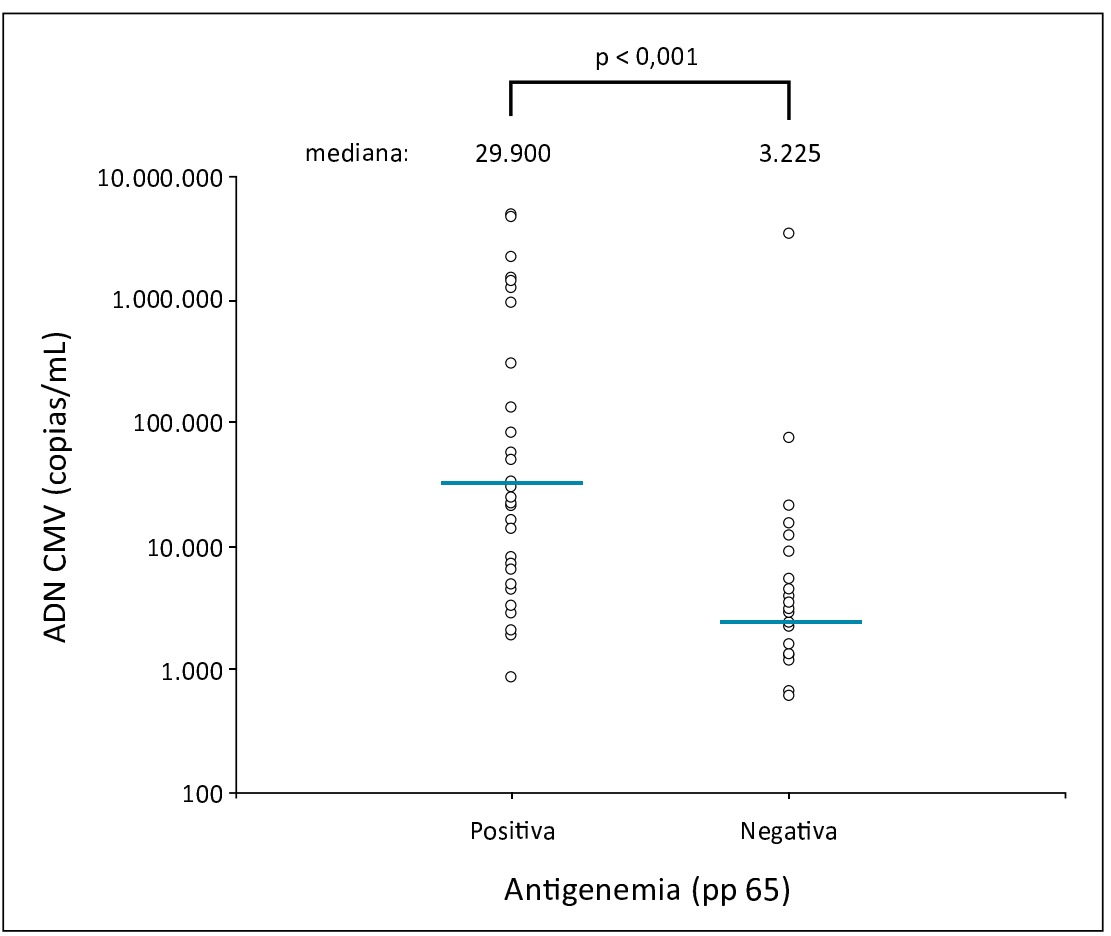

Figura 2. Comparación entre los valores positivos obtenidos por RPC-TR y los valores de antigenemias positivas y negativas. En la figura se comparan los valores de RPC-TR positivos expresados como copias por mililitro con el número de antigenemias positivas y negativas. Las líneas horizontales representan la mediana de los valores en ambos grupos (test Mann-Whitney, $\mathrm{p}<0,001$ ). 


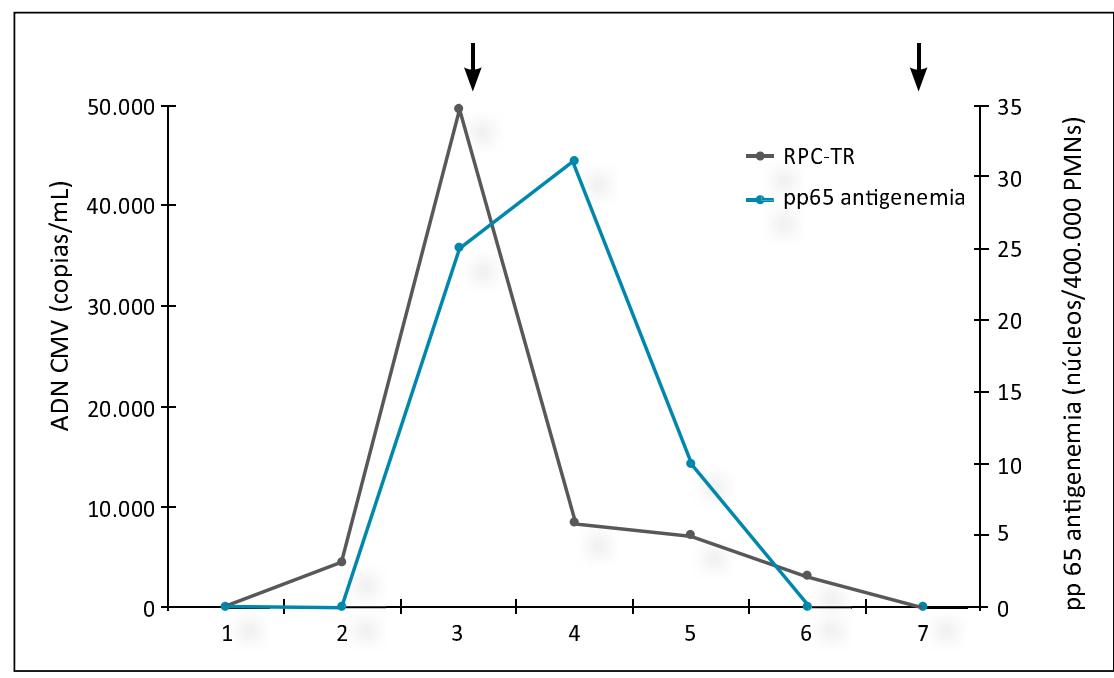

Figura 3. Detección de CMV en un seguimiento semanal de un paciente mediante las técnicas de RPC-TR y antigenemia. En el gráfico se representan los valores de RPC-TR (copias/mL, línea gris) y antigenemia (núcleos/400.000 PMNs, línea verde) obtenidos durante el seguimiento semanal de un paciente de la unidad de TPH con un episodio de infección activa por CMV. Las flechas negras indican el inicio y término del tratamiento antiviral (ganciclovir 10 mg/kg/día).

Tabla 1. Detección de citomegalovirus por las técnicas de antigenemia y reacción de polimerasa en cadena en tiempo real (RPC-TR) en 219 muestras de sangre en niños sometidos a trasplante

\begin{tabular}{|c|c|c|c|c|}
\hline \multirow{5}{*}{ 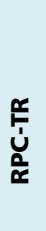 } & \multicolumn{4}{|c|}{ Antigenemia } \\
\hline & & Positiva & Negativa & Tota \\
\hline & Positiva & 33 & 37 & 70 \\
\hline & Negativa & 2 & 147 & 149 \\
\hline & Total & 35 & 184 & 219 \\
\hline
\end{tabular}

resultados obtenidos por antigenemia y RPC-TR para CMV $(r=0,43 ; p<0,00001)$ en leucocitos periféricos de pacientes sometidos a TPH, describiendo una detección de CMV 10 días antes por RPC-TR que por antigenemia, y un número de copias/mL en la RPC-TR significativamente más alto en pacientes con antigenemia positiva comparado con pacientes con antigenemia negativa. Mengoli y cols ${ }^{13}$, encontraron, en pacientes con trasplante de órganos sólidos, un mayor número de infectados con CMV en sangre utilizando RPC-TR, y de Oña y cols ${ }^{14}$ por su parte, comunicaron que en el seguimiento de pacientes con infección por $\mathrm{CMV}$, la antigenemia se vuelve negativa con mayor precocidad que la RPC-RT, tal como lo observado en la Figura 3, donde se grafican los valores de encontrados en la detección de CMV utilizando antigenemia y RPC-TR en un paciente sometido a TPH seguido durante siete semanas.

Uno de los aspectos que dificulta la implementación de la RPC-TR como instrumento de diagnóstico es su costo. Sin embargo, al comparar los insumos y reactivos necesarios para realizar las técnicas de antigenemia y RPC-TR, los costos son comparables ${ }^{8}$. No obstante, para el caso de la RPC-TR es necesario contar con una infraestructura adecuada, además de personal altamente capacitado para mantener la confiabilidad y reproducibilidad de esta técnica, lo que dificulta su implementación masiva. En este sentido, la utilización de técnicas de diagnóstico molecular, junto con el desarrollo de centros diagnóstico en el sector público, como el nuestro, permite la implementación de este tipo de técnicas a un menor costo si se compara con la compra de servicios a centros privados. Por otra parte, la disponibilidad de controles certificados para la implementación de esta metodología, permitirá optimizar el estándar de estas reacciones, como también el aumento de laboratorios que cuenten con estas herramientas diagnosticas. Nuestro próximo paso será determinar los valores de corte para el diagnóstico de la infección activa por $\mathrm{CMV}$, como también detectar ADN de CMV en otros fluidos corporales tales como lavado bronco-alveolar (LBA). Chemaly y cols ${ }^{15}$, informaron que la detección de CMV en LBA se relacionó significativamente con neumonía por CMV en pacientes con trasplante pulmonar y que la RPC-TR en LBA tuvo un valor predictor mayor que la realizada en sangre.

Nuestro trabajo tiene varias limitaciones. No se relacionó el resultado de la antigenemia y/o carga viral en sangre con la presentación y/o evolución clínica en estos pacientes. Por otra parte, para obtener los valores de sensibilidad, especificidad y los valores predictores para la RPC-TR, se utilizó como referencia la antigenemia y no el cultivo, debido a que este último no es utilizado de rutina en la práctica clínica. Esta situación, podría explicar el bajo valor predictor positivo obtenido para la RPC-TR, que logró detectar un número significativamente mayor de muestras positivas para CMV en comparación con la antigenemia.

En conclusión, la determinación cuantitativa de ADN de CMV por RPC-TR en sangre realizada en este estudio resultó ser una técnica sensible con alto valor predictor negativo, al compararla con la antigenemia. Su utilización como una herramienta de diagnóstico permitiría una detección más precoz de la infección activa por CMV en pacientes sometidos a trasplante y facilitaría el diagnóstico, tratamiento y seguimiento de estos pacientes.

\section{Resumen}

Antecedentes: Las infecciones por citomegalovirus (CMV) corresponden a una importante causa de morbilidad y mortalidad en pacientes sometidos a trasplantes. Hasta la fecha, la detección de CMV en células infectadas en sangre periférica mediante la técnica de inmunofluo- 
rescencia (antigenemia) es la más utilizada para el diagnóstico y monitorización de la infección por este agente. Sin embargo, en el último tiempo la cuantificación de la carga de ácido nucleico (ADN) de CMV en sangre mediante la técnica de reacción de polimerasa en cadena en tiempo real (RPC-TR) ha permitido la detección de CMV de forma más rápida, sensible y específica. Objetivos: Comparar las técnicas de antigenemia y RPC-TR para la detección de CMV en sangre en niños sometidos a trasplante de órganos sólidos y trasplante de precursores hematopoyéticos (TPH) en el Hospital Dr. Luis Calvo Mackenna. Metodología: En un estudio prospectivo de seguimiento preventivo de reactivación se detectó la presencia de CMV en muestras de sangre utilizando las técnicas de RPC-TR y antigenemia. Resultados: Se analizaron 219 muestras de sangre, correspondiente a
68 niños sometidos a trasplante de hígado, riñón y TPH. De las muestras analizadas, 147 fueron negativas y 33 positivas para CMV utilizando ambas técnicas. Treinta y siete muestras resultaron ser positivas sólo por RPCTR y dos sólo por antigenemia. Tomando en cuenta la antigenemia como referencia, la RPC-TR mostró una sensibilidad, especificidad, valor predictor positivo y negativo de $94 \%, 80 \%, 34 \%$ y $99 \%$, respectivamente. El índice de concordancia entre ambas técnicas tuvo un valor de kappa $=0,528$. Conclusión: La determinación cuantitativa de ADN de CMV por RPC-TR es una técnica sensible, con un gran valor predictor negativo comparada con la antigenemia. Los resultados obtenidos en este trabajo apoyan el uso de RPC-TR para el diagnóstico y tratamiento oportuno de las infecciones activas por CMV en niños sometidos a trasplantes.

\section{Referencias}

1.- Madi N, Al-Nakib W, Mustafa AS, Saeed T, Pacsa A, Nampoory MR. Detection and monitoring of cytomegalovirus infection in renal transplant patients by quantitative real-time PCR. Med Princ Pract 2007; 16: 268-73.

2.- Leruez-Ville M, Ouachee M, Delarue R, Sauget AS, Blanche S, Buzin A, et al. Monitoring cytomegalovirus infection in adult and pediatric bone marrow transplant recipients by a real-time PCR assay performed with blood plasma. J Clin Microbiol 2003; 41: 2040-6.

3.- Salazar E M, Alba G A, Delucchi B A, Hunter M B, Godoy L J, Ferrario B M, et al. Cytomegalovirus infection and disease in pediatric solid organ transplantation. Experience in a Chilean multiorganic transplantation center. Rev Chil Infectol 2009; 26: 311-7.

4.- Blank B S, Meenhorst P L, Mulder J W, Weverling G J, Putter H, Pauw W, et al. Value of different assays for detection of human cytomegalovirus (HCMV) in predicting the development of HCMV disease in human immunodeficiency virus-infected patients. J Clin Microbiol 2000; 38: 563-9.

5.- Piiparinen H, Helantera I, Lappalainen M, Suni J, Koskinen P, Gronhagen-Riska C, et al.
Quantitative PCR in the diagnosis of CMV infection and in the monitoring of viral load during the antiviral treatment in renal transplant patients. J Med Virol 2005; 76: 367-72.

6.- Caliendo A M, Schuurman R, Yen-Lieberman B, Spector S A, Andersen J, Manjiry R, et al. Comparison of quantitative and qualitative PCR assays for cytomegalovirus DNA in plasma. $\mathrm{J}$ Clin Microbiol 2001; 39: 1334-8.

7.- Ikewaki J, Ohtsuka E, Satou T, Kawano R, Ogata M, Kikuchi H, et al. Real-time PCR assays based on distinct genomic regions for cytomegalovirus reactivation following hematopoietic stem cell transplantation. Bone Marrow Transplant 2005; 35: 403-10.

8.- Li H, Dummer J S, Estes W R, Meng S, Wright P F, Tang Y W. Measurement of human cytomegalovirus loads by quantitative real-time PCR for monitoring clinical intervention in transplant recipients. J Clin Microbiol 2003; 41: 187-91.

9.- Paris C, Kopp K, King A, Santolaya M E, Zepeda A J, Palma J. Cytomegalovirus infection in children undergoing hematopoietic stem cell transplantation in Chile. Pediatr Blood Cancer 2009; 53: 453-8.

10.- Levitsky J, Singh N, Wagener M M, Stosor V, Abecassis M, Ison M G. A survey of CMV prevention strategies after liver transplantation. Am J Transplant 2008; 8: 158-61.

11.- Boeckh M, Huang M, Ferrenberg J, Stevens-Ayers T, Stensland L, Nichols W G, et al. Optimization of quantitative detection of cytomegalovirus DNA in plasma by realtime PCR. J Clin Microbiol 2004; 42: 1142-8.

12.- Griscelli F, Barrois M, Chauvin S, Lastere S, Bellet D, Bourhis JH. Quantification of human cytomegalovirus DNA in bone marrow transplant recipients by real-time PCR. J Clin Microbiol 2001; 39: 4362-9.

13.- Mengoli C, Cusinato R, Biasolo M A, Cesaro S, Parolin C, Palu G. Assessment of CMV load in solid organ transplant recipients by pp65 antigenemia and real-time quantitative DNA PCR assay: correlation with pp67 RNA detection. J Med Virol 2004; 74: 78-84.

14.- de Ona M, Melon S, Galarraga M C, Palacio A, Lambert J L, Bernardo M J, et al. Comparison of cytomegalovirus pp-65 antigenemia assay and plasma DNA correlation with the clinical outcome in transplant recipients. Transpl Int 2005; 18: 43-6.

15.- Chemaly R F, Yen-Lieberman B, Chapman J, Reily A, Bekele B N, Gordon S M, et al. Clinical utility of cytomegalovirus viral load in bronchoalveolar lavage in lung transplant recipients. Am J Transplant 2005; 5: 544-8.S 